\title{
Effect of Bentonite Clay on the Growth of Gaeumannomyces graminis var. tritici and on its Interactions with Antagonistic Bacteria
}

\author{
By R. CAMPBELL* AND J. M. EPHGRAVE \\ Departments of Botany and Microbiology, University of Bristol, Bristol BS8 1UG, U.K.
}

(Received 2 July 1982; revised 27 August 1982)

The effects were studied of increasing concentrations of bentonite clay on the interactions between the fungal pathogen Gaeumannomyces graminis var. tritici and two bacterial antagonists. Clay increased the growth rate of G. graminis; this increase was statistically significant, though small, and could have been due to an effect on water availability. The effectiveness of one of the bacterial culture filtrates in restricting the fungal growth was reduced by the clay, though antagonism was maintained in the presence of bacterial cells. The clay may adsorb some of the bacterial toxins, and lowered water availability may increase bacterial antagonism before it significantly reduces fungal growth. Antagonism by the other bacterium was not affected by clay.

\section{INTRODUCTION}

Gaeumannomyces graminis var. tritici is the causal fungus of take-all disease of wheat and, by attacking the roots, it may result in the death of a plant or severe reduction in growth and yield. There are no effective chemical control methods or disease-resistant cultivars. The possible biological control of this disease has therefore been extensively studied. Lal (1939) examined interactions between the pathogen and other soil micro-organisms. More recently the use of other fungi and bacteria for biological control has been considered (see examples in Baker \& Cook, 1974; Schippers \& Gams, 1979; Asher \& Shipton, 1981). Bacteria have been isolated which gave some control of the disease under small-scale field trial conditions (Faull \& Campbell, 1979; Campbell \& Faull, 1979) but the effectiveness of some of the isolates varied between field sites. Soil type was considered to be at least partly responsible for this and electron microscope studies showed clay to be adsorbed to both the hyphae and some bacteria in the natural soil.

The aim of the present study was therefore to investigate the effect of clay on the interaction between the fungus and the antagonistic bacteria. Clay could cause an effect in many ways, such as by adsorbing nutrients and possibly toxins, and by the reduction in available water in the soil because of the adsorption and the formation of smaller pores. Stotzky (1972) has shown that montmorillonite clays may inhibit the growth of some fungi but the effects on fungal-bacterial interactions are more complicated: some bacteria antagonistic in agar culture are not antagonistic in soils with clays, while others are more antagonistic in soil than in culture. In particular Bacillus cereus and a Bacillus sp. were not antagonistic in soil or clay mixtures (Rosenzweig \& Stotzky, 1979). Effects vary with the type of clay mineral and with the concentration of the clay.

The effects of water availability on $G$. graminis have been studied in relation to disease occurrence under increased moisture conditions in the field. This fungus grows best in wet soils (matric potentials -1.2 to -1.5 bar) and the growth rate is reduced to half at -20 bar (Cook $e t$ al., 1972). Cook \& Papendick (1970) reported various experiments showing that bacteria are more sensitive than fungi to even slightly lowered water potential in soil and may show serious growth reductions at -5 or -10 bar. They suggest that bacterial antagonism may be reduced by lowered water availability before most fungi are seriously inhibited. 
In view of all these possible complications it was decided to conduct the present experiments in sand/clay mixtures of known composition, with sufficiently high water potential to allow both fungus and antagonist to grow well, and using pure cultures of all organisms. This experimental arrangement is far removed from the field conditions which originally prompted the investigation but could enable some of the conflicting interactions to be analysed.

\section{METHODS}

Gaeumannomyces graminis var. tritici was isolated from infected wheat roots and kept on whole, autoclaved wheat seeds. Inoculum was prepared by growing the fungus on $2 \%(\mathrm{w} / \mathrm{v})$ malt agar and cutting discs, $6 \mathrm{~mm}$ in diameter, from the colony with a sterile cork borer. Bacillus cereus var. mycoides and a coryneform bacterium were isolated from wheat roots growing in take-all decline soils and in a non-decline soil, respectively: these two isolates were selected in preliminary trials which tested for ability to inhibit G. graminis. The bacteria were kept as freezedried cultures and sub-cultured on to 1/10 Tryptic Soy agar (Difco Tryptic Soy broth at 1/10 recommended strength, plus agar); shake cultures for inoculum were prepared in $1 / 10$ Tryptic Soy broth at $20^{\circ} \mathrm{C}$.

The growth medium was washed sand with $3 \%(\mathrm{w} / \mathrm{w})$ ground wheat seed: this attempted to provide similar conditions to growth of the fungus in soil. In clay treatments the sand was partially replaced by montmorillonite clay (BDH, bentonite) to 1,5 or $10 \%$ dry weight. Water was added and the mixture was packed loosely into glass Petri dishes and autoclaved twice at $120^{\circ} \mathrm{C}$ for $20 \mathrm{~min}$. Gaeumannomyces graminis was inoculated at the side of the dish, and its radial growth rate measured at $2 \mathrm{~d}$ or $3 \mathrm{~d}$ intervals: in this medium it grows as a uniform front across the dish (Fig. $1 b$ ) and is easily seen from both above and below. The bacterial treatments were applied, at the same time as G. graminis, as an evenly distributed spray generated by filter-sterilized air under pressure. There were four treatments: (1) the control, of $2 \mathrm{ml}$ sterile water per plate; (2) the same volume of culture filtrate (centrifuged and Millipore filtered) from shake cultures of either B. cereus or the coryneform; (3) washed cells of the bacteria in the same volume of sterile water at $10^{5}$ cells $\mathrm{ml}^{-1} ;(4)$ the same volume and number of bacteria in the unseparated complete culture. Numbers were determined by counting with a Neubauer Chamber.

The above experiments were done at similar total water contents. In a separate experiment the effect of controlling water availability was checked. The complete culture of $\boldsymbol{B}$. cereus was used, with either sand or sand plus $10 \%$ bentonite. The relationship between total water content and matric potential was first determined for the two mixtures, using a pressure plate (Soil Moisture Equipment Company, Santa Barbara, Calif., U.S.A.). The sand or sand/clay mixtures were then autoclaved with the minimum of water: the total volume of sterile water, culture, etc. to be addèd.was calculated so that the two treatments ( 0 and $10 \%$ clay) were at the same matric potential of approximately $-0 \cdot 15$ bar $(-15 \mathrm{kPa})$. A third treatment was also set up by adjusting the water added to the $10 \%$ bentonite to give a matric potential of approximately $-0.6 \mathrm{bar}(-60 \mathrm{kPa})$. These treatments are very wet in terms of field soil but do allow comparison between sand or sand/clay media at identical water availability levels. There was no evidence from the growth of the fungus that these water potentials and clay concentrations seriously reduced oxygen availability. The effect of the antagonists was again assessed by measuring the radial growth of $G$. graminis at $2 \mathrm{~d}$ or $3 \mathrm{~d}$ intervals.

The diameters of the G. graminis colonies after $20 \mathrm{~d}$ growth were subjected to analysis of variance, followed by Duncan's multiple range test (Steel \& Torrie, 1960) to assess differences between particular treatments.

\section{RESULTS}

Preliminary trials in agar showed that the coryneform produced inhibition zones typical of the production of soluble antibiotics, while $B$. cereus was often overgrown by $G$. graminis which was later lysed (Fig. $1 a$ ). In sand culture $G$. graminis alone normally grew evenly across the plate (Fig. $1 b$ ) but was severely inhibited or killed in the presence of the antagonists (Fig. $1 c, d$ ).

\section{Effects of clay and bacterial treatments}

Examination of the data for radial growth against time for the 16 treatments for each bacterium indicated that the effectively antagonistic bacterial treatments caused a constant reduction in overall growth rate and not an extended lag phase followed by the same growth rate. It was therefore considered valid to use the final set of data for analysis after $20 \mathrm{~d}$ growth when the fastest growing treatment or replicates were approaching complete cover of the dishes.

Since the clay would have altered the available water, even though total water content was similar in the different treatments, comparisons of the bacterial treatments within a clay treatment were valid but any differences between clay treatments could have been caused by the clay itself or by changes in water availability. 

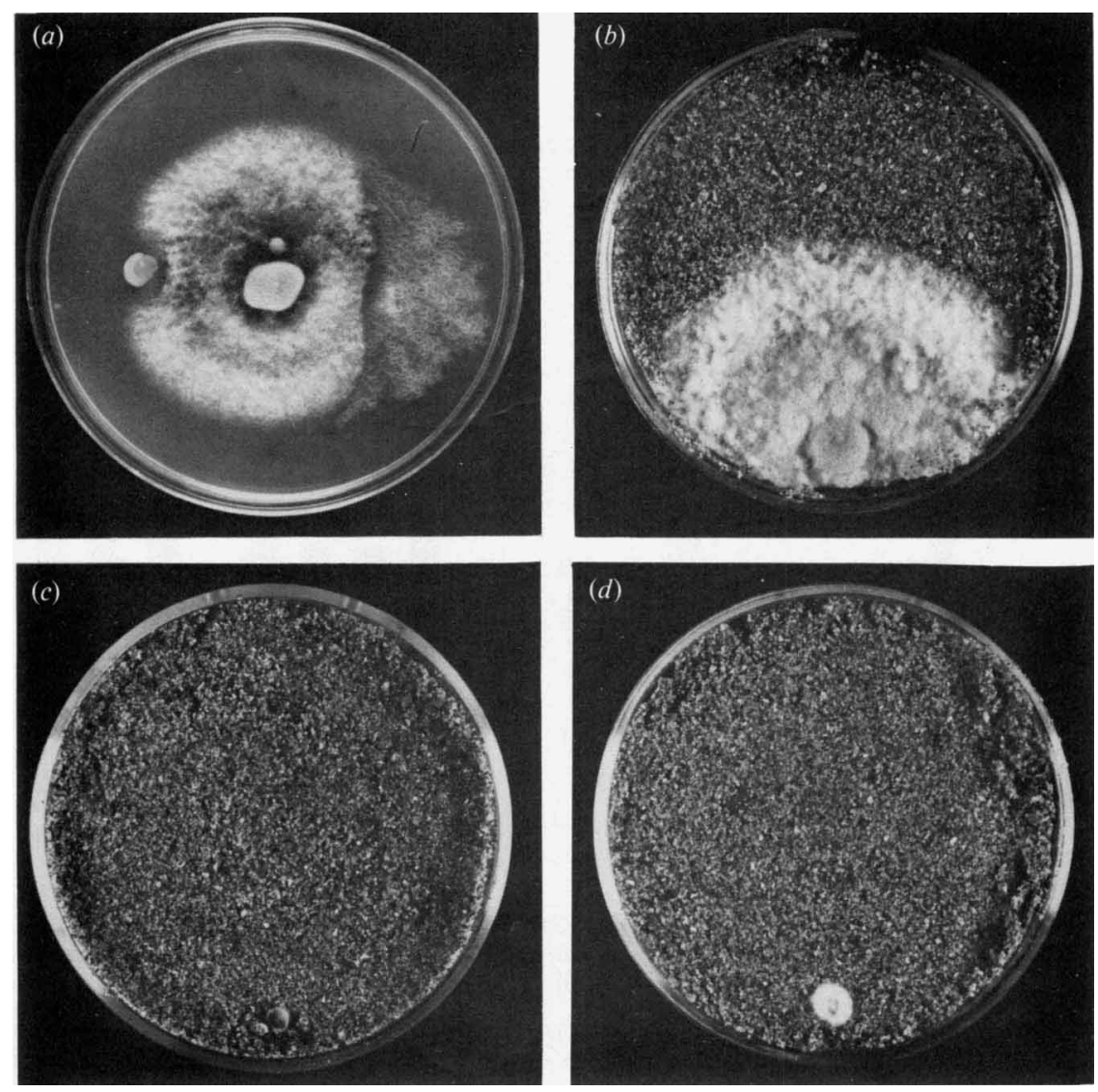

Fig. 1. Growth form and inhibition of G. graminis in plate culture. (a) On 1/10 Tryptic soy agar showing inhibition by the coryneform (left) and overgrowth with subsequent lysis by $B$. cereus (right). (b) In sand culture, the water control with normal growth of $G$. graminis (sand $+5 \%$ clay). (c) G. graminis killed by the coryneform (sand, no clay). (d) Very restricted growth of $G$. graminis in the presence of the coryneform (sand $+5 \%$ clay).

With the coryneform bacterium the clay treatments (Fig. 2) were just significantly different (at $5 \%$ probability level), while the bacterial treatments showed highly significant differences (at $0.1 \%$ probability level). Detailed comparisons showed no differences between the clay treatments for each of the different bacterial treatments; bacterial treatments inhibited fungal growth regardless of clay treatments. Growth of G. graminis on the water control treatment was increased by the addition of clay and this increase in growth was significant (at $1 \%$ probability level) with $5 \%$ clay. Within all the clay treatments (Fig. 2) the growth of the fungus on the water control was significantly greater than on the bacterial treatments; that is, all the bacterial treatments inhibited growth. Filtrate tended to be least inhibitory especially at the highest clay level, but was not significantly different from the other two clay treatments (Fig. 2).

With $B$. cereus there were very significant $F$ ratios both between clay treatments and between bacterial treatments (Fig. 3). The water control again showed increased growth of G. graminis on the addition of clay and this difference was significant for all clay concentrations. The complete culture treatment stayed inhibitory in relation to the water control at all clay concentrations (Fig. 3), though at $5 \%$ clay it was less effective than at 0,1 or $10 \%$. Cells and filtrate worked significantly less well $(1 \%$ probability level) in the presence of clay, though the cells did still inhibit in relation to the water control. The filtrate, however, failed to cause growth inhibition at 5 and $10 \%$ clay (Fig. 3 ). In sand, i.e. $0 \%$ clay, there were small differences between the bacterial treatments, filtrate being just the least effective. The differences between the bacterial 


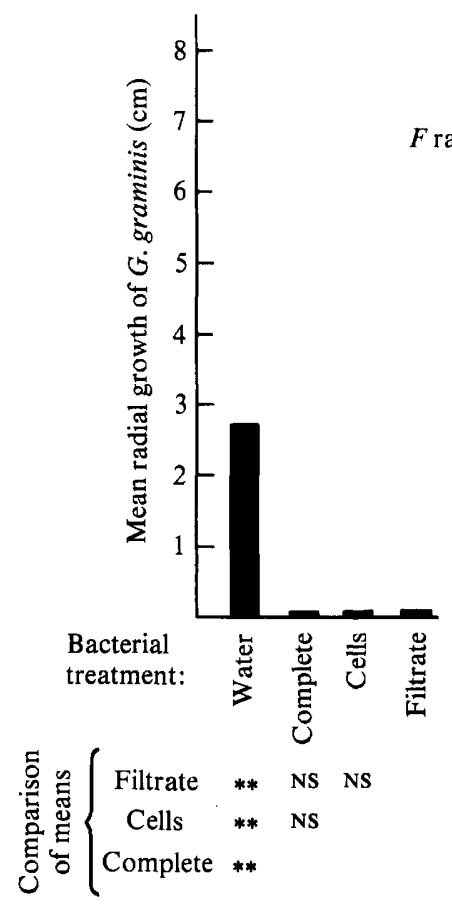

Clay concn: $\quad 0 \%$

All fractions

inhibit G. graminis

$F$ ratios: between clay treatments $3 \cdot 5^{*}$ between bacterial treatments $66.4^{* * *}$ interaction

1.4 (Ns)

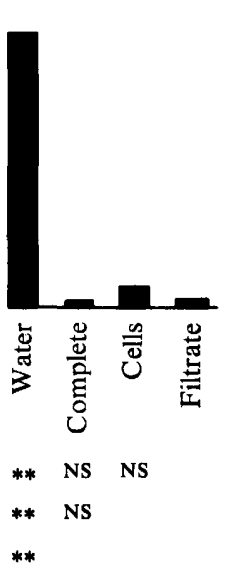

$1 \%$

All fractions inhibit G. graminis No clay effect

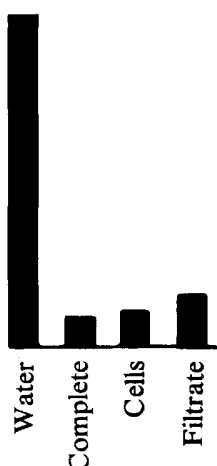

** NS NS

** NS

**

$5 \%$

All fractions inhibit G. graminis No clay effect

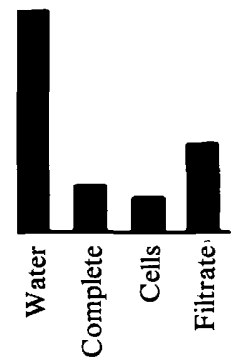

** NS NS

** NS

**

$10 \%$

All fractions inhibit $G$. graminis No clay effect

Fig. 2. Effect of culture fractions from the coryneform bacterium on the radial growth of G. graminis at various clay concentrations. The results are means of four replicates. Water $=$ control, no bacterial fractions added; complete = cells and culture filtrate added; cells = washed bacterial cells added; filtrate $=$ sterile culture filtrate added. Clay at $0 \%=$ sand + ground wheat grain only; other clay percentages consist of this mixture with the addition of the indicated amount of clay. The $F$ ratios from the analysis of variance are given at the top of the figure. The significance of the differences between the means of the individual bacterial treatments within a clay concentration, by Duncan's Multiple Range test, are shown below the histograms. Ns, Not significant; $*$, significant at the $5 \%$ probability level; $* *$, significant at the $1 \%$ probability level; $* * *$, significant at the $0 \cdot 1 \%$ probability level.

treatments became greater at higher clay concentrations and filtrate was always the least effective inhibitor. The complete treatment produced the greatest inhibition of G. graminis growth except at $5 \%$ clay.

\section{Effect on B. cereus of controlled available water}

Montmorillonite clay had most effect on the antagonistic ability of $B$. cereus; the coryneform was antagonistic regardless of clay content. It is possible that the clay effects could have been due to reduced water availability. To test this there were six treatments (Fig. 4). Bacillus cereus was always inhibitory though not always equally effective (compare the same clay-water treatments with and without $B$. cereus). If the available water was constant, with no antagonist, there was no significant increase in the growth of $G$. graminis on the addition of clay.

In comparing the sand and the sand/clay medium with the same water availability there was a significant decrease in bacterial antagonism when clay was present. There was also a water effect on the bacterium. When the clay concentration was held constant and the water availability dropped to $-60 \mathrm{kPa}, B$. cereus was more inhibitory than at $-15 \mathrm{kPa}$. Gaeumannomyces graminis showed no significant effect of the reduction in water available, even though it did grow marginally less. 


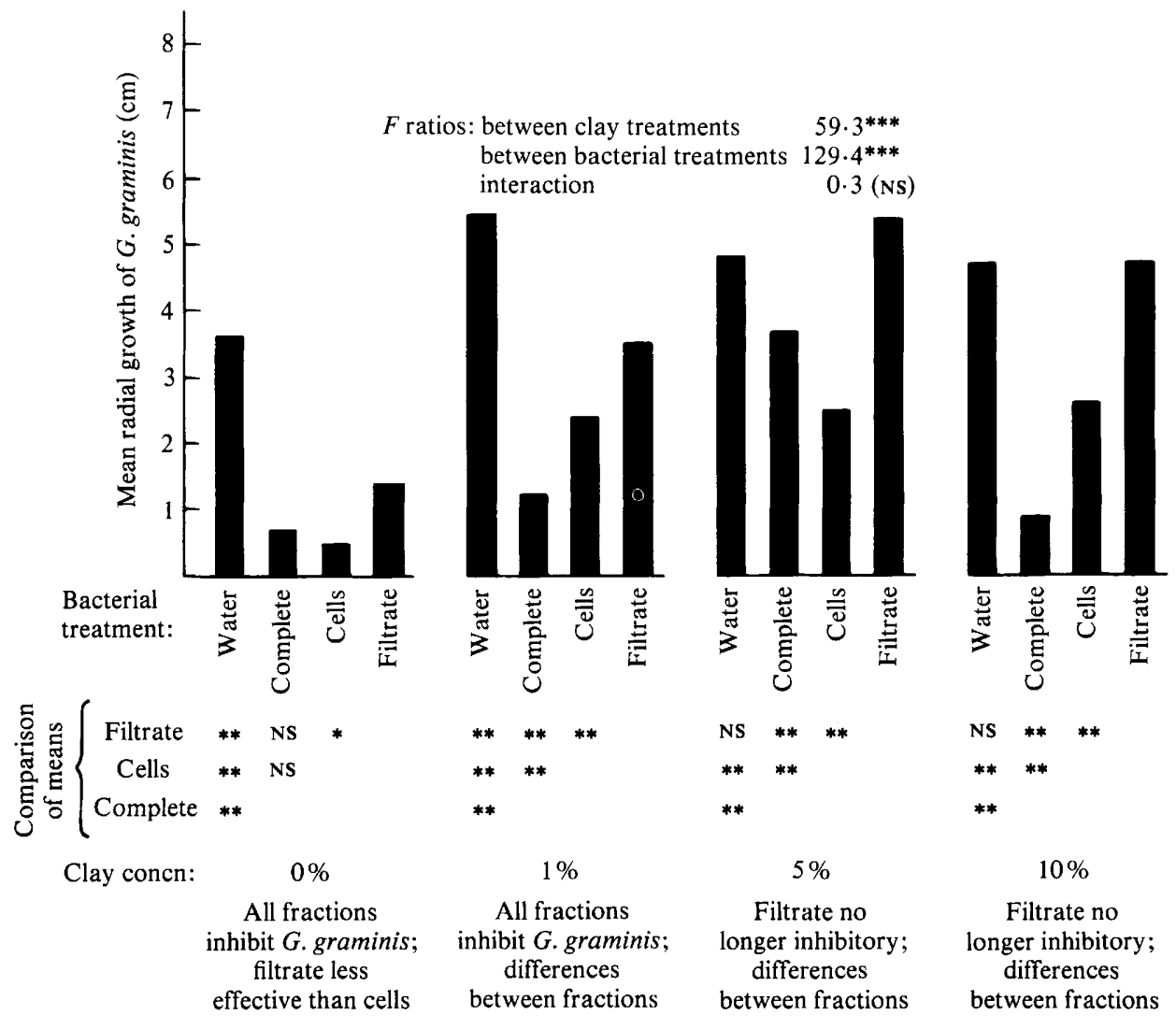

Fig. 3. Effect of culture fractions from B. cereus var. mycoides on the radial growth of $G$. graminis at various clay concentrations. Abbreviations and details as in Fig. 2.

\section{DISCUSSION}

The increased linear growth rate of $G$. graminis in the presence of clay is in contrast to the findings of Stotzky (1972) with other fungi. The effect, though usually significant, was small, and disappeared when the available water was held constant.

The coryneform seemed to be the most effective antagonist, and clay had very little effect on this ability in these pure-culture studies. This bacterium produced an inhibition zone on agar plates and the cell-free culture filtrate inhibited G. graminis growth. This implies that the coryneform produces an extracellular water-soluble toxin.

The effect of clay on the culture filtrates of $B$. cereus suggested that a soluble toxin was also produced by the bacterium but that it was being adsorbed or inactivated by the clay. It is not known why $5 \%$ clay was especially active in reducing the effect of the $B$. cereus filtrate. As the filtrates from both bacteria reduced growth in sand, there must be a soluble inhibitor in both, but that from $B$. cereus was presumably adsorbed by clay while that from the coryneform was not.

There may be a second inhibitory mechanism in $B$. cereus which requires the presence of the cells. It is notable that in agar cultures and in slide culture the coryneform shows a zone of inhibition of the classical pattern (Fig. $1 a$ ), as would be expected for the production of a soluble toxin. Bacillus cereus, however, is overgrown by $G$. graminis but subsequently lyses the hyphae (Fig. 1 $a$; Faull \& Campbell, 1979). This suggests an additional lytic agent which does not diffuse far or which is actually attached to the bacterial wall. The production of both inhibitors, particularly the soluble one, seems to be very dependent on cultural conditions. 


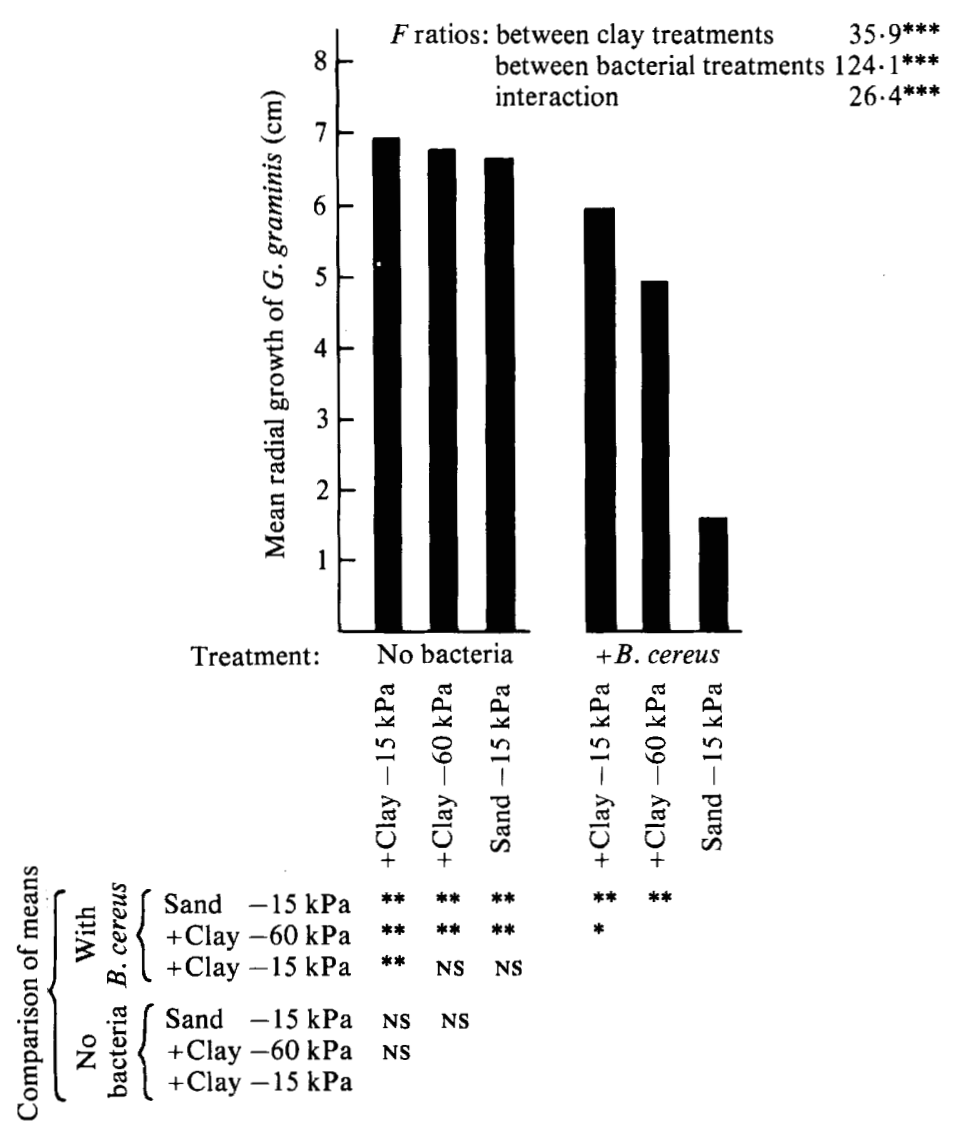

Fig. 4. Effect of the complete culture of B. cereus var. mycoides on the radial growth of $G$. graminis in sand and a sand/clay mixture ( $10 \%$ clay) at $-15 \mathrm{kPa}(-0.15 \mathrm{bar})$ matric potential and in the sand/clay mixture at $-60 \mathrm{kPa}(-0.6 \mathrm{bar})$, compared with the same treatments without the complete bacterial culture. The results are means of five replicates. $F$ ratios and the significance of the differences between the means of individual treatments are given. Abbreviations as in Fig. 2.

Rosenzweig \& Stotzky (1979) found that B. cereus and a Bacillus sp. isolated from laboratory air produced zones of inhibition to fungi in agar culture but were not effective in soil. This contrasts with the present studies with $B$. cereus var. mycoides.

The supplementary experiment on water availability confirmed that there was an effect of bentonite (montmorillonite) in reducing the antagonism by $B$. cereus, probably by adsorption of inhibitor, as has been shown for other organisms (Skinner, 1956; Soulides 1969). In contrast, Stotzky (1972) found that montmorillonite could increase antagonism between bacteria and some other fungi.

The lack of significant effect on $G$. graminis growth of the reduction in water availability from $-15 \mathrm{kPa}$ to $-60 \mathrm{kPa}$ is in agreement with the literature: this is still very wet for the fungus and significant growth reduction would only be expected at much lower water potentials (Cook et al., 1972). Reduced water availability does, however, affect the interaction between the bacterium and the fungus, making the bacterium more antagonistic before it significantly reduces the growth of the fungus.

It is very difficult to extrapolate from these results to any possible field use of the antagonists for biological control of take-all, but obviously the clay content of some soils would reduce the effectiveness of some antagonists and this factor must be considered when selecting potential biocontrol agents. 


\section{REFERENCES}

Asher, M. J. C. \& ShIPTON, P. J. (1981). Biology and Control of Take-all. London: Academic Press.

BAKER, K. F. \& CoOK, R. J. (1974). Biological Control of Plant Pathogens. San Francisco: Freeman.

Campbell, R. \& Faull, J. L. (1979). Biological control of Gaeumannomyces graminis: field trials and ultrastructure of the interaction between the fungus and a successful antagonistic bacterium. In Soil-borne Plant Pathogens, pp. 603-609. Edited by B. Schippers \& W. Gams. London: Academic Press.

COOK, R. J. \& PAPENDICK, R. I. (1970). Effects of soil water on microbial growth, antagonism and nutrient availability in relation to soil-borne diseases of plants. In Root Diseases and Soil-borne Pathogens, pp. 81-88. Edited by T. A. Tousson, R. V. Bega \& P. E. Nelson. Berkeley: University of California Press.

CoOK, R. J., Papendick, R. I. \& Griffin, D. M. (1972). Growth of two root-rot fungi as affected by osmotic and matric water potentials. Soil Science Society of America Proceedings 36, 78-82.

FAULL, J. L. \& CAMPBELL, R. (1979). Ultrastructure of the interaction between the take-all fungus and antagonistic bacteria. Canadian Journal of Botany 57, $1800-1808$.
LAL, A. (1939). Interaction of soil micro-organisms with Ophiobolus graminis Sacc., the fungus causing the take-all disease of wheat. Annals of Applied Biology 26, 247-261.

Rosenzweig, W. D. \& Stotzky, G. (1979). Influence of environmental factors on antagonism of fungi by bacteria in soil: clay minerals and $\mathrm{pH}$. Applied and Environmental Microbiology 38, 1120-1126.

SkINNER, F. (1956). The effect of adding clays to mixed cultures of Streptomyces albidoflavus and Fusarium culmorum. Journal of General Microbiology 14, 393405.

SCHIPPERS, B. \& GAMS, W. (1979). Soil-borne Plant Pathogens. London: Academic Press.

SOULIDES, D. A. (1969). Antibiotic tolerance of soil microflora in relation to type of clay mineral. Soil Science 107, 105-107.

STEel, R. G. D. \& TORRIE, J. H. (1960). Principles and Procedures of Statistics. New York: McGraw-Hill.

StotzKY, G. (1972). Activity, ecology and population dynamics of micro-organisms in the soil. $C R C$ Critical Reviews in Microbiology 2, 59-137. 